\title{
Glycation of fibrinogen in uncontrolled diabetic patients and the effects of glycaemic control on fibrinogen glycation
}

\author{
Marlien Pieters ${ }^{a}$, Danie G. van Zyl ${ }^{b}$, Paul Rheeder ${ }^{c}$, Johann C. Jerling ${ }^{a}$, \\ Du Toit Loots ${ }^{a}$, Francois H. van der Westhuizen ${ }^{d}$, Louise T. Gottsche ${ }^{a}$ and \\ John W. Weisel ${ }^{\mathrm{e}}$
}

${ }^{a}$ Department of Nutrition, North-West University, South Africa

${ }^{b}$ Department of Internal Medicine, University of Pretoria, South Africa

${ }^{c}$ Division of Clinical Epidemiology, University of Pretoria, South Africa

${ }^{\mathrm{d}}$ Department of Cell and Developmental Biology, University of Pennsylvania, USA

${ }^{\mathrm{e}}$ School of Biochemistry, North-West University, South Africa

\section{Abstract}

\section{Introduction}

Evidence exists for a relationship between glycaemic control and macrovascular disease. Non-enzymatic glycation of proteins may explain this relationship in part. We investigated the effect of blood glucose control, under out-patient conditions, on fibrinogen glycation as well as the relationship between glycated fibrinogen and glycaemic control using a new sensitive method for the measurement of glycated fibrinogen.

\section{Materials and methods}

Blood samples were taken from twenty subjects with uncontrolled Type 2 diabetes $(\mathrm{HbA} 1 \mathrm{c}>7 \%)$ to determine the levels of glycation. The subjects were then treated with 
insulin in order to control blood glucose. Twenty age and BMI matched non-diabetic subjects were included as a reference group.

\section{Results}

The subjects with diabetes had significantly higher mean fibrinogen glycation at baseline than the non-diabetic subjects (7.84 vs 3.89 mol glucose / mol fibrinogen; $p<0.001$ ). After control of blood glucose, fibrinogen glycation was reduced significantly in the subjects with diabetes ( 7.84 to $5.24 \mathrm{~mol}$ glucose / mol fibrinogen; $p<0.0002$ ). The change in glycation during the intervention correlated significantly with the change in capillary glucose in the diabetic group $(r=0.6, p=0.005)$. Fibrinogen glycation was comparable to HbA1c in predicting glycaemic control $(p=0.54)$. Fibrinogen glycation correlated best with the average fasting capillary glucose of the preceding 5-8 days $(r=0.54, p=0.014)$.

\section{Conclusion}

We conclude that glucose control under out-patient conditions decreases fibrinogen glycation in subjects with Type 2 diabetes and that glycated fibrinogen compares well with $\mathrm{HbAlc}$ in its relation to glycaemic control.

Abbreviations: HbA1c, glycated heamoglobin; CVD, cardiovascular disease; LDL, low density lipoprotein; BMI, body mass index; EDTA, Ethylenediaminetetraacetic acid; ROC curves, receiver operator characteristic curves

\section{Article Outline}

Materials and methods

Study design

Subjects

Type 2 diabetic subjects

Non-diabetic controls

Study protocol 


\section{Blood sampling}

Analytical procedures

Statistical analysis

Results

Discussion

Acknowledgements

References

Diabetes mellitus is a worldwide pandemic with a projected increase in prevalence from 171 million people in 2000 to 366 million in 2030 [1]. Both Type 1 and 2 diabetes are powerful and independent risk factors for cardiovascular disease (CVD), such that patients with diabetes have a two to fourfold increased risk for developing CVD along with increased atherosclerosis [2] and [3].

The major vascular complications of diabetes are atherosclerosis and microvascular disease, constituting the main cause of mortality and morbidity in diabetes mellitus. Data from the Diabetes Control and Complications Trial have unequivocally established a causal relationship between chronic hyperglycemia and microvascular disease [4] and [5]. The relationship between chronic hyperglycemia and macrovascular complications is not as well defined. The bulk of the evidence does however, suggest a relationship between glycaemic control and the extent of macrovascular complications [6], [7] and [8].

Pathophysiologically, hyperglycemia might cause atherosclerosis by several mechanisms, the most important of which is most likely the non-reactive enzymatic glycation of plasma proteins and lipids and the formation of reactive advanced glycation end products (AGE's) mediated by oxidative stress mechanisms [9]. Advanced glycation end products potentially modulate initiating steps in atherosclerosis through blood-vessel wall interactions, triggering of inflammatory-proliferative processes, propagation of inflammation and vascular perturbation as well as through promotion of the formation of oxidized LDL [10]. 
Fibrinogen has been shown to be an independent risk marker for CVD [11]. Fibrinogen may contribute significantly to the increased CVD risk in patients with diabetes both in that they generally have elevated fibrinogen levels and that fibrinogen undergoes nonenzymatic glycation in the presence of uncontrolled blood glucose levels in the diabetic subject [12], [13], [14] and [15]. This glycation can alter fibrinogen structure/function, which may then result in the formation of a tight and rigid fibrin network that is resistant to lysis [16], [17] and [18]. Measuring glycated fibrinogen and determining how glycation changes with glucose control together with comparing the ability of glycated fibrinogen to monitor glycaemic control with that of $\mathrm{HbAlc}$ may shed more light on the relationship between glycaemic control and macrovascular complications.

Although glycated fibrinogen has been suggested as a short term index of glycaemic control based on its short half life of three to four days [14], [19] and [20], this is the first study to determine the effect of glycaemic control on fibrinogen glycation in out-patient subjects and to demonstrate how well it compares with HbAlc in its relation to glycaemic control using a new sensitive method for the determination of fibrinogen glycation. The study was done under out-patient conditions, in order to determine the applicability of these measurements to the majority of subjects with diabetes and not only to those receiving intensive in-hospital treatment.

\section{Materials and methods}

\section{Study design}

In this, parallel, controlled intervention, twenty black African subjects with Type 2 diabetes, uncontrolled (HbAlc $>7 \%$ ) on oral hypoglycaemic agents, were included and treated with insulin, until glycaemic control was achieved (four out of five subsequent readings within normal glucose range). The patients then had to remain controlled for eight days before end blood samples were drawn. This eight day period was chosen in order to provide enough time for unglycated fibrinogen to be produced (half-life 34 days) after glycaemic control had been achieved. Twenty non-diabetic black African subjects were included as a reference group in order to control for variation over time. All subjects signed informed consent and ethical approval was obtained form the ethics 
committees of both the University of Pretoria and the North-West University, South Africa.

\section{Subjects}

Type 2 diabetic subjects

Inclusion criteria: Patients had to be uncontrolled ( $\mathrm{HbA1c}>9 \%)$ on maximum dose combination oral hypoglycaemic medication; BMI $>25 \mathrm{~kg} / \mathrm{m}^{2} ; 40-65$ years of age; blood pressure sufficiently controlled not to necessitate treatment change during intervention $(<140 / 90 \mathrm{mmHg})$.

Exclusion criteria: Major surgery in the preceding six months; macrovascular complications; disease that can influence haemostasis (e.g. thrombocytopenia, cancer, liver disease) patients on aspirin, warfarin, steroids, hormone replacement therapy or nonsteroidal anti-inflammatory drugs; proteinuria on urine dipstick (>300 mg/day) or acute infection.

\section{Non-diabetic controls}

Non-diabetic subjects with matching anti-hypertensive drug-use (hidrochlorothiazide, ACE-inhibitor- Perindopril and nifedipine - Adalat), age, gender and BMI were recruited. The same inclusion and exclusion criteria as for the subjects with diabetes were adhered to. Baseline oral glucose tolerance tests were done to rule out diabetes.

\section{Study protocol}

The intervention in the diabetic group consisted of 3 phases. Phase 1: On the first visit, the subjects were seen by a diabetes educator. They were taught how to do self glucose monitoring, co-ordination of insulin use with meals, symptoms and management of hypoglycaemic events and the use of glucagon. Fasting capillary glucose was measured daily for 1 week.

Phase 2: Subjects received 10 IU basal analogue insulin Glargine (Lantus, SanofiAventis Pharmaceuticals, Paris, France) daily at 22:00 in addition to current treatment of maximum dose oral hypoglycaemic treatment. Metformin use was unchanged from before and during the intervention. Insulin administration was adjusted individually until 
four out of five subsequent fasting glucose values were less than $7.2 \mathrm{mmol} / \mathrm{L}$ [21]. Sulphonylureas was stopped.

Phase 3: Post-prandial glucose was now controlled with pre-meal administration of short-

acting insulin Aspart (Novo Nordisk, Bagsværd, Denmark) as required. Once both fasting and post-prandial (glucose $<10 \mathrm{mmol} / 1$ [21]) glycaemic control was achieved, the subjects remained on treatment for eight days. Capillary glucose was measured twice daily, fasting and once post-prandially throughout the intervention. Baseline blood samples and anthropometric measurements were collected at the end of phase 1 and end samples and measurements at the end of phase 3. Blood samples of non-diabetic subjects were drawn within one week of their matched diabetic subject's blood sampling.

\section{Blood sampling}

Fasting venous blood samples were drawn with minimal stasis by a medical doctor before 10 AM. For the determination of insulin and lipids, blood was left to clot for preparation of serum. For venous glucose determination, blood was collected into sodium fluoride tubes. EDTA blood was collected for the determination of HbAlc. Citrate blood was collected for the determination of fibrinogen and fibrinogen glycation. Blood was centrifuged for $15 \mathrm{~min}$ at $2000 \mathrm{~g}$ at $4{ }^{\circ} \mathrm{C}$ within $30 \mathrm{~min}$ of collection. Serum and plasma were stored at $-82{ }^{\circ} \mathrm{C}$ until analysis.

\section{Analytical procedures}

Capillary glucose was measured with glucometers (Accu-Chek Active, Roche Diagnostics, Mannheim, Germany). Fasting insulin was measured with an enzyme-linked immunosorbent assay (ELISA) method on the Immulite 2000 Analyzer (Diagnostic Products Corporation, Los Angeles, California, USA). Plasma glucose, baseline HbA1c and serum lipids were measured on a Synchron LX clinical System (Beckman Coulter Inc., Fullerton, CA, USA). Low-density lipoprotein cholesterol was calculated by using the Friedewald formula [22]. Insulin resistance was calculated using the homeostasis model assessment (HOMA) as: (fasting insulin $\times$ fasting venous glucose) / 22.5 [23] Plasma fibrinogen (modified Clauss method) was measured on an Automated Coagulation Laboratory 200 (Instrumentation Laboratories, Milan, Italy) (between run 
$\mathrm{CV}=3 \%$ ). Fibrinogen was purified from the plasma of each subject using IF-1 affinity chromatography as described previously [24]. Purified fibrinogen was run on $10 \%$ SDS PAGE gels to confirm purity and the absence of degradation of the fibrinogen preparations. Fibrinogen glycation was measured with a two-reagent enzymatic assay $\left(\right.$ GlyPro $^{\circledR}$ assay, Genzyme Diagnostics, Cambridge, MA (between run CV $=5 \%$ ). This is a specific enzymatic method for the direct measurement of glycated proteins in serum or plasma. The first reagent digests the proteins and subsequently releases glycated protein fragments. Ketoamine oxidase in the second reagent facilitates the specific oxidation of the ketoamine bond of the glycated protein fragment substrate. Liberation of hydrogen peroxide allows a colorimetric determination of the amount of glycated protein in an endpoint reaction. Absorbance at $550 \mathrm{~nm}$ is measured after the addition of reagent 1 and again after reagent 2 . Results are calculated as follows:

\section{Glycafed protein $(\mathrm{mmol} / \mathrm{L})=\Delta \Delta$ sample $/ \Delta \Delta$ ealibrator $X$ calibrator valtwe $(\mu \mathrm{mol} / \mathrm{L})$.}

\section{Statistical analysis}

A power calculation was done using 1 standard deviation as a clinical significant difference, as a defined clinical significant difference is not known for the main outcome variable, fibrinogen glycation. To achieve a difference of 1 standard deviation at $80 \%$ power, 5\% significance, each group should consist of at least 16 individuals. The computer software package, Statistica (Statsoft Inc., Tulsa, Oaklahoma, USA) was used for statistical analysis. Data was tested for normality. Normally distributed data is presented as the mean (standard deviation) and not normally distributed data as median (25th; 75th percentile). Differences in baseline characteristics as well as differences in changes during the intervention between the two groups were determined using the $t$-test for independent samples for parametric data and the Mann-Whitney $U$ test for nonparametric data. Differences from baseline to end within each group were determined using the paired $t$-test. Spearman-correlation was used for all correlations. In order to determine how well glycated fibrinogen compared to HbAlc in monitoring glycaemic control, agreement was assessed between glycated fibrinogen and the current standard 
measure for blood glucose control - HbAlc, as well as fasting venous glucose, utilizing the area under the Receiver Operator Characteristic (ROC) curves. ROC curves were also used to determine the optimal threshold level of glycated fibrinogen to indicate glycaemic control. The sensitivity and specificity for this glycated fibrinogen value was determined, for both $\mathrm{HbA1c}$ and fasting venous glucose level as reference.

\section{Results}

Two non-diabetic subjects failed to return for end blood sampling and were hence excluded from the study. Table 1 presents the baseline characteristics of the two groups. They were comparable regarding age, BMI, blood pressure, fibrinogen concentration and fasting insulin. The diabetic group had significantly higher fasting venous glucose, $\mathrm{HbAlc}$, insulin resistance, triglycerides and fibrinogen glycation. Only one of the subjects smoked and alcohol consumption was infrequent. Baseline glycated fibrinogen correlated significantly with baseline $\mathrm{HbA1c}(r=0.8, p<0.001)$, fasting venous glucose $(r=0.69, p<0.001)$ and the average of the preceding four days' fasting capillary glucose $(r=0.5, p<0.035)$ for the total group.

Table 1.

Baseline characteristics of subjects

\begin{tabular}{|l|l|l|}
\hline Variables & $\begin{array}{l}\text { Type 2 diabetic } \\
\text { subjects }\end{array}$ & $\begin{array}{l}\text { Non-diabetic } \\
\text { subjects }\end{array}$ \\
\hline Patients $(n)$ & 20 & 18 \\
\hline Sex (male/female) & $6 / 14$ & $7 / 11$ \\
\hline Age (years) & $53.0(8.29)$ & $52.9(7.13)$ \\
\hline Body mass index $\left(\mathrm{kg} / \mathrm{m}^{2}\right)$ & $30.8(6.16)$ & $31.8(5.89)$ \\
\hline Fasting venous glucose $(\mathrm{mmol} / \mathrm{L})$ & $14.6(8.12)^{\mathrm{a}}$ & $5.18(1.24)^{\mathrm{a}}$ \\
\hline Fasting Insulin $(\mathrm{mU} / \mathrm{L})^{\mathrm{c}}$ & $11.0(6.70 ; 15.8)$ & $13.7(8.9 ; 28.8)$ \\
\hline Fibrinogen $(\mathrm{g} / \mathrm{L})$ & $4.25(0.80)$ & $4.02(0.86)$ \\
\hline $\begin{array}{l}\text { Fibrinogen glycation }(\mathrm{mol} \text { glucose/mol } \\
\text { fibrinogen) }\end{array}$ & $7.84(2.68)^{\mathrm{a}}$ & $3.89(0.86)^{\mathrm{a}}$ \\
\hline
\end{tabular}




\begin{tabular}{|c|c|c|}
\hline Variables & $\begin{array}{l}\text { Type } 2 \text { diabetic } \\
\text { subjects }\end{array}$ & $\begin{array}{l}\text { Non-diabetic } \\
\text { subjects }\end{array}$ \\
\hline $\operatorname{HbAlc}(\%)^{\mathrm{c}}$ & $11.7(9.50 ; 13.8)^{\mathrm{a}}$ & $5.60(5.30 ; 5.90)^{\mathrm{a}}$ \\
\hline Systolic blood pressure (mmHg) & $140.5(22.5)$ & $143.3(26.4)$ \\
\hline Diastolic blood pressure $(\mathrm{mmHg})$ & $86.6(8.15)$ & $89.8(13.1)$ \\
\hline Total cholesterol (mmol/L) & $4.84(1.49)$ & $4.54(0.71)$ \\
\hline Triglycerides $(\mathrm{mmol} / \mathrm{L})^{\mathrm{c}}$ & $1.80(1.25 ; 2.50)^{\mathrm{b}}$ & $1.05(0.80 ; 1.25)^{\mathrm{b}}$ \\
\hline $\begin{array}{l}\text { High density lipoprotein cholesterol } \\
(\mathrm{mmol} / \mathrm{L})^{\mathrm{c}}\end{array}$ & $0.9(0.75 ; 1.3)$ & $0.9(0.8 ; 1.25)$ \\
\hline $\begin{array}{l}\text { Low density lipoprotein cholesterol } \\
(\mathrm{mmol} / \mathrm{L})\end{array}$ & $2.86(1.03)$ & $2.88(0.83)$ \\
\hline Insulin resistance (HOMA) ${ }^{c}$ & $5.18(3.99 ; 6.95)^{\mathrm{b}}$ & $3.11(2.29 ; 7.42)^{\mathrm{b}}$ \\
\hline Duration of diabetes (years) & $11.0(8.0)$ & \\
\hline
\end{tabular}

Note: ${ }^{\mathrm{a}} \mathrm{P}<0.001 ;{ }^{\mathrm{b}} \mathrm{P}<0.05 ;{ }^{\mathrm{c}}$ Data not normally distributed and therefore reported as median $(25,75$ percentile $)$; Insulin resistance $=($ fasting insulin $\times$ fasting venous glucose) / 22.5 .

The average duration between baseline and end blood sampling was 69.5 (range: 15-148) days and 75 (range: 8-154) days for the diabetic and non-diabetic subjects respectively. There was a significant increase in BMI from baseline to end in the subjects with diabetes $(p=0.001)$ (Table 2). Fasting venous glucose and fibrinogen glycation decreased significantly during the intervention $(p<0.001$ and $p<0.001)$. No significant changes were seen in the non-diabetic group, except for a slight increase in glucose $(p=0.05)$. The increase in BMI and the decrease in venous glucose concentration and fibrinogen glycation in the diabetic group differed significantly from the responses in the nondiabetic group. There was a significant correlation $(r=0.52 ; p=0.001)$ between the decrease in fibrinogen glycation and venous glucose in the total group. This correlation was not significant for the diabetic subjects alone, however the correlation between the decrease in fibrinogen glycation and the decrease in capillary glucose (an average of 4 days' values at baseline and end) was significant $(r=0.6 ; p=0.005)$. 
Table 2.

Differences between diabetic and non-diabetic subjects of selected variables for the intervention period

\begin{tabular}{|c|c|c|c|c|c|c|c|c|c|}
\hline \multirow[t]{2}{*}{ Variable } & \multicolumn{4}{|c|}{ Type 2 diabetic subjects $(n=20)$} & \multicolumn{4}{|c|}{ Non-diabetic controls $(n=18)$} & \multirow{2}{*}{$\begin{array}{l}\text { Changes between } \\
\text { groups (deltas) } \\
p\end{array}$} \\
\hline & Baseline & End & Delta & $p$ & Baseline & End & Delta & $p$ & \\
\hline Body mass index $\left(\mathrm{kg} / \mathrm{m}^{2}\right)$ & $\begin{array}{l}30.8 \\
(6.16)\end{array}$ & $\begin{array}{l}32.2 \\
(6.80)\end{array}$ & $\begin{array}{l}1.79 \\
(2.08)\end{array}$ & 0.001 & $\begin{array}{l}31.7 \\
(5.89)\end{array}$ & $\begin{array}{l}32.0 \\
(6.02)\end{array}$ & $\begin{array}{l}0.30 \\
(0.81)\end{array}$ & 0.14 & 0.009 \\
\hline Fasting glucose $(\mathrm{mmol} / \mathrm{L})$ & $\begin{array}{l}14.6 \\
(8.12)\end{array}$ & $\begin{array}{l}6.72 \\
(2.57)\end{array}$ & $\begin{array}{l}-7.88 \\
(8.90)\end{array}$ & 0.0008 & $\begin{array}{l}5.18 \\
(1.24)\end{array}$ & $\begin{array}{l}5.63 \\
(1.37)\end{array}$ & $\begin{array}{l}0.46 \\
(0.91)\end{array}$ & 0.05 & 0.0003 \\
\hline Fibrinogen $(\mathrm{g} / \mathrm{L})$ & $\begin{array}{l}4.25 \\
(0.80)\end{array}$ & $\begin{array}{l}4.36 \\
(0.79)\end{array}$ & $\begin{array}{l}0.11 \\
(0.95)\end{array}$ & 0.62 & $\begin{array}{l}4.02 \\
(0.86)\end{array}$ & $\begin{array}{l}3.85 \\
(0.86)\end{array}$ & $\begin{array}{l}-0.16 \\
(0.72)\end{array}$ & 0.35 & 0.33 \\
\hline $\begin{array}{l}\text { Fibrinogen glycation (mol } \\
\text { glucose/mol fibrinogen) }\end{array}$ & $\begin{array}{l}7.84 \\
(2.68)\end{array}$ & $\begin{array}{l}5.24 \\
(1.65)\end{array}$ & $\begin{array}{l}-2.60 \\
(2.60)\end{array}$ & 0.0002 & $\begin{array}{l}3.89 \\
(0.86)\end{array}$ & $\begin{array}{l}3.75 \\
(0.62)\end{array}$ & $\begin{array}{l}-0.19 \\
(0.70)\end{array}$ & 0.27 & 0.0007 \\
\hline
\end{tabular}


The ability of glycated fibrinogen to predict blood glucose control as controlled (mean blood glucose $<6.4 \mathrm{mmol} / \mathrm{L}$ ) or uncontrolled (mean blood glucose $>6.4 \mathrm{mmol} / \mathrm{L}$ ) was assessed by utilizing ROC curves with fasting venous glucose values and $\mathrm{HbA1c}$ (control $<7 \%$ ) as reference variables. The area under the ROC curve of baseline glycated fibrinogen is $0.94(0.82,0.99)$ with baseline HbA1c as reference (Fig. 1). A glycated fibrinogen value of $5.62 \mathrm{~mol}$ glucose / mol fibrinogen has a $78.9 \%(54.4,93.8)$ sensitivity and $100 \%(80.3,100.0)$ specificity to predict glycaemic control with HbAlc as reference. This relates to a positive likelihood ratio of 13.42 for glycated fibrinogen to predict glycaemic control with $\mathrm{HbAlc}$ as gold standard. If the area under the ROC curve for glycated fibrinogen is compared with that of $\mathrm{HbA1c}$ with fasting plasma glucose as reference, the area under the ROC curve for glycated fibrinogen is $0.85(0.70,0.95)$, and that of HbAlc is $0.89(0.74,0.97)$ (Fig. 2). This difference is not statistically significant.

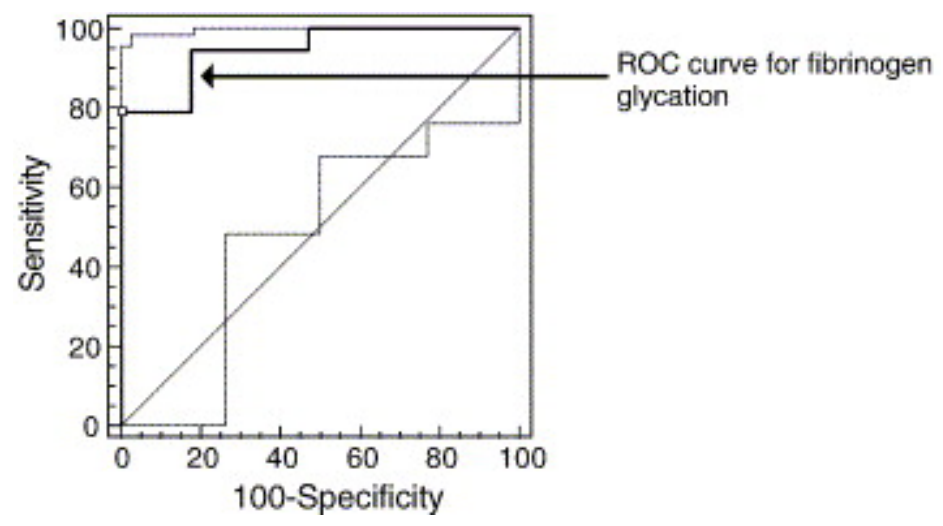

Figure 1. ROC curve for fibrinogen glycation with $\mathrm{HbAlc}$ as reference value.

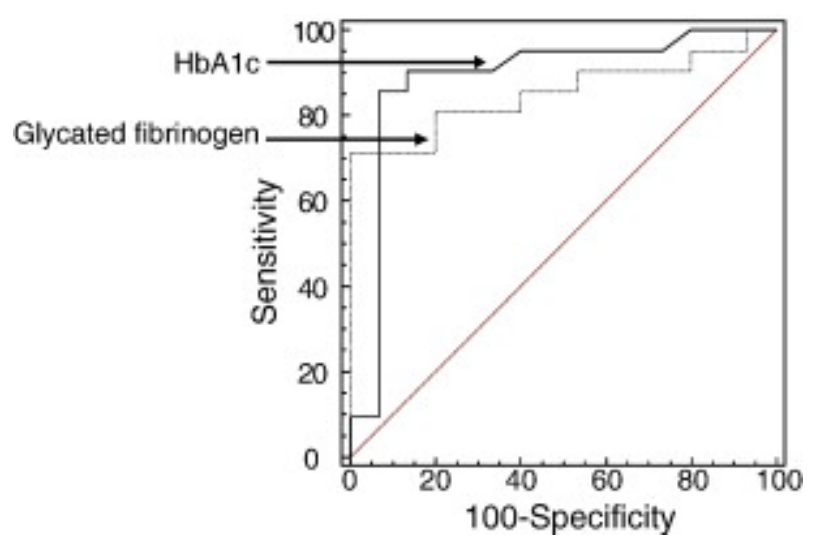


Figure 2. Comparison of ROC curves of glycated fibrinogen and HbAlc using fasting venous glucose as reference.

In order to estimate for which time period glycated fibrinogen corresponds to glucose concentrations, the end value of glycated fibrinogen was correlated to the average fasting capillary glucose of different 4-day time intervals preceding the date of end blood sampling, using the daily recorded capillary values (Table 3). Glycation of fibrinogen showed a strong correlation with the preceding 12 days $(r=0.53 ; p=0.017)$, with the preceding 5-8 days as the most important contributor $(r=0.54 ; \mathrm{p}=0.014)$ of the 12 day period.

Table 3.

Correlation of glycated fibrinogen with the average fasting capillary glucose concentration over different time intervals

\begin{tabular}{|l|l|l|}
\hline Time intervals & \multicolumn{2}{|l|}{ Fibrinogen glycation } \\
\hline & $\boldsymbol{r}$ & $\boldsymbol{p}$ \\
\hline 0-4 days & 0.31 & 0.74 \\
\hline 5-8 days & 0.54 & 0.014 \\
\hline 9-12 days & 0.33 & 0.16 \\
\hline 0-8 days & 0.47 & 0.038 \\
\hline 0-12 days & 0.53 & 0.017 \\
\hline Day 0 - day & & \\
\hline
\end{tabular}

Day 0 - day of end blood sampling. Days 4,5,8,9,12 - the amount of days preceding end blood sampling.

\section{Discussion}

This study had two main aims. The first was whether controlling blood glucose levels of out-patients subjects with Type 2 diabetes would result in decreased fibrinogen glycation using a sensitive method for measurement of glycated fibrinogen. The second aim, which has never been tested before was to determine how well glycated fibrinogen compares to 
HbAlc in its relation to glycaemic control. We were also able to provide information regarding the time-interval at which glycated fibrinogen correlated best with fasting capillary glucose.

Although there was no difference between the mean fibrinogen concentration of the two groups, both had high fibrinogen concentrations on an average. Subjects with Type 2 diabetes have been shown to have high fibrinogen [25]. The high fibrinogen concentration in the non-diabetic subjects is also in agreement with previous work from our group [26] as well as others [27] who have reported higher fibrinogen concentrations in black people compared to Caucasians. The diabetic group was significantly more insulin resistant than the non-diabetic group, while fasting insulin concentrations were similar. This is most likely a result of beta cell failure due to insulin resistance present in subjects with diabetes. Body mass index increased significantly in the diabetic group during the intervention. This is probably due to the exogenous insulin they received at the beginning of the study. There are several explanations for why insulin treatment results in weight gain: reduced glucosuria, leading to reduced urinary calorie loss and increased glucose metabolism, accumulation of adiposity or increased appetite [6]. The average glycation of fibrinogen in the subjects with diabetes was approximately twice as high as that of the non-diabetic subjects (7.84 vs 3.89 mol glucose / mol fibrinogen). This significantly improved after achievement of glycaemic control (33\% decreased glycation) although not to a level seen in the non-diabetic subjects. Two other studies have reported decreased fibrinogen glycation after treatment of uncontrolled diabetic subjects, Hammer et al. [28] and Ardawi et al. [29]. It is not clear, however, from their results whether Type 1 or type 2 diabetes was investigated. Their results are reported after intensive treatment of three and six days. Our results show that this decrease in fibrinogen glycation can also be achieved in the majority of diabetic subjects who attend out-patient clinics at hospitals. The reason why the decrease in glycated fibrinogen correlated significantly with the decrease in fasting capillary glucose but not with fasting venous glucose, is probably because venous glucose measurement is a single measurement at a point in time. The capillary glucose values used for the correlation was an average of four days' values, which is a better reflection of the true fasting glucose levels around the time of blood sampling, as opposed to the single measurement of 
venous glucose. This is further substantiated by the fact that a significant correlation was obtained between the decrease in fibrinogen glycation and the decrease in fasting venous glucose, when the samples size was increased by including also the results of the nondiabetic subjects.

The level of glycation reported in this study, is in agreement with levels found by Suzuki et al. [30] (8.1 $\pm 3.64 \mathrm{~mol}$ glucose / mol fibrinogen in diabetic subjects and $3.13 \pm 1.29 \mathrm{~mol}$ glucose / mol fibrinogen in normal subjects). Lütjens et al. [31] however, found lower levels in both Type 1 diabetic subjects and healthy volunteers. Using two different methods, they found $1.3 \pm 0.19$ and $1.33 \pm 0.21 \mathrm{~mol}$ glucose / mol fibrinogen for subjects with uncontrolled Type 1 diabetes and $1.06 \pm 0.08$ and $0.95 \pm 0.17 \mathrm{~mol}$ glucose / mol fibrinogen for healthy volunteers. A possible explanation for the different levels of glycation may be that both our group and the group of Suzuki et al. [30] used commercially available kits for the determination of glycated protein, where as Lütjens et al. [31] used the thiobarbituric acid method [32] and high performance liquid chromatography according to the method of Schleicher and Wieland [33]. Other groups have also measured fibrinogen glycation in vivo, but they report their results as glycated fibrinogen expressed as percentage of total fibrinogen [28] and [34].

Glycated fibrinogen has been suggested as a predictor of glycaemic control [28], [29], [30] and [35]. Exactly how well it compares to HbAlc in monitoring glycaemic control has, however, not yet been determined, until now. Results from this study indicated that glycated fibrinogen is comparable to HbAlc in its relation to glycaemic control in subjects with Type 2 diabetes. When using HbA1c as the gold standard, the area under the ROC curve of glycated fibrinogen is 0.94 . The ROC curve is used to assess the discriminatory value of a diagnostic test. In ninety four percent of cases, subjects will be correctly classified as either having good or poor control based on the HbA1c. A glycated fibrinogen value above the optimum threshold level of $5.62 \mathrm{~mol}$ glucose / mol fibrinogen is 13.42 times more likely to occur in subjects with HbA1c uncontrolled ( $>7 \%)$ than in subjects who are well controlled (positive likelihood ratio). There was also no significant difference between the ROC curves of glycated fibrinogen and HbAlc in predicting glycaemic control with fasting venous glucose as a reference. It has to be kept in mind 
that fibrinogen is an acute phase protein and plasma levels may change considerably during acute infections.

Due to its short half life, glycated fibrinogen is an ideal marker for monitoring short term glycaemic control and therefore the early assessment of the effectiveness of a treatment regime or a research study with a short duration. This is especially important in developing countries where home daily glucose monitoring is not an option as very few diabetic patients have their own glucometers. In cross sectional data glycated fibrinogen has been shown to correlate with blood glucose at the same time or one day earlier [30] or three to four days prior to measurement [36]. Although not the main aim of the study, by correlating the end fibrinogen glycation level with the average fasting capillary glucose of different 4-day time-intervals (comparable to fibrinogen half-life) we were able to ascertain with which time-interval fibrinogen glycation correlated best. Measurement of glycated fibrinogen at each time-interval would have provided stronger evidence. Our results suggest that glycated fibrinogen correlated best with the preceding 12 days of which the preceding 5-8 days made the most important contribution. This is somewhat in agreement with the results from Hammer et al. [28] and Ardawi et al. [29], who respectively reported a $15 \%$ decrease in fibrinogen glycation after three days and $33.4 \%$ after 6 days of treatment of newly diagnosed diabetic subjects to similar levels of fasting blood glucose $(9.9 \pm 2.3 \mathrm{mmol} / \mathrm{L}$ and $9.7 \pm 1.4 \mathrm{mmol} / \mathrm{L}$ respectively). Even though similar blood glucose levels were achieved, a more pronounced decrease in glycation was seen over the somewhat longer period of 6 days.

The extent of in vivo glycation of proteins is furthermore a complex function of the glucose concentration it is exposed to, the duration of exposure, the half-life of the protein as well as the intrinsic susceptibility to non-enzymatic glycation. Austin et al. [34] have shown that overall acidity or basicity relates fairly well with the extent of glycation. Fibrinogen, being an acidic protein, is therefore glycated much less in vivo than in vitro. This relatively low intrinsic susceptibility to non-enzymatic glycation may further explain why we found fibrinogen correlating better with a longer time-interval than just its half life.

We have adapted and implemented a sensitive method for the determination of glycated fibrinogen. With this we were able to show that fibrinogen is significantly more glycated 
in subjects with Type 2 diabetes than non-diabetic subjects and that even in out-patient subjects fibrinogen glycation can successfully be reduced through control of blood glucose. Glycated fibrinogen correlates with and compares well with $\mathrm{HbA1c}$ in monitoring glycaemic control. The results from this study aid in the understanding of the relationship between glycaemic control and macrovascular disease in that glycation of plasma proteins, specifically fibrinogen, is indeed sensitive to fluctuations in glycaemic control.

\section{References}

[1] S. Wild, G. Roglic, A. Green, R. Sicree and H. King, Global prevalence of diabetes: estimates for the year 2000 and projections for 2030, Diabetes Care 27 (5) (2004), pp. 1047-1053.

[2] J. Stamler, O. Vaccaro, J.D. Neaton and D. Wentworth, Diabetes, other risk factors, and 12-yr cardiovascular mortality for men screened in the Multiple Risk Factor Intervention Trial, Diabetes Care 16 (2) (1993), pp. 434-444.

[3] M. Wei, S.P. Gaskill, S.M. Haffner and M.P. Stern, Effects of diabetes and level of glycemia on all-cause and cardiovascular mortality. The San Antonio Heart Study, Diabetes Care 21 (7) (1998), pp. 1167-1172.

[4] The effect of intensive treatment of diabetes on the development and progression of long-term complications in insulin-dependent diabetes mellitus. The Diabetes Control and Complications Trial Research Group, N Engl J Med 329 (14) (1993), pp. 977-986. [5] Retinopathy and nephropathy in patients with type 1 diabetes four years after a trial of intensive therapy. The Diabetes Control and Complications Trial/Epidemiology of Diabetes Interventions and Complications Research Group, N Engl J Med 342 (6) (2000), pp. 381-389.

[6] M.S. Boyne and C.D. Saudek, Effect of insulin therapy on macrovascular risk factors in type 2 diabetes, Diabetes Care 22 (Suppl 3) (1999), pp. C45-C53.

[7] D.M. Nathan, P.A. Cleary, J.Y. Backlund, S.M. Genuth, J.M. Lachin and T.J. Orchard et al., Intensive diabetes treatment and cardiovascular disease in patients with type 1 diabetes, $N$ Engl J Med 353 (25) (2005), pp. 2643-2653. 
[8] S.M. Haffner, Epidemiological studies on the effects of hyperglycemia and improvement of glycemic control on macrovascular events in type 2 diabetes, Diabetes Care 22 (Suppl 3) (1999), pp. C54-C56.

[9] M. Brownlee, The pathobiology of diabetic complications: a unifying mechanism, Diabetes 54 (6) (2005), pp. 1615-1625.

[10] G. Basta, A.M. Schmidt and R. De Caterina, Advanced glycation end products and vascular inflammation: implications for accelerated atherosclerosis in diabetes, Cardiovasc Res 63 (4) (2004), pp. 582-592.

[11] J. Danesh, S. Lewington, S.G. Thompson, G.D. Lowe, R. Collins and J.B. Kostis et al., Plasma fibrinogen level and the risk of major cardiovascular diseases and nonvascular mortality: an individual participant meta-analysis, JAMA 294 (14) (2005), pp. 17991809.

[12] E.J. Dunn and R.A. Ariens, Fibrinogen and fibrin clot structure in diabetes, Herz 29 (5) (2004), pp. 470-479.

[13] A. Lutjens, A.A. te Velde, E.A. vd Veen and M.J. vd, Glycosylation of human fibrinogen in vivo, Diabetologia 28 (2) (1985), pp. 87-89.

[14] M.R. Hammer, P.N. John, M.D. Flynn, A.J. Bellingham and R.D. Leslie, Glycated fibrinogen: a new index of short-term diabetic control, Ann Clin Biochem 26 (Pt 1) (1989), pp. 58-62.

[15] M.S. Ardawi, H.N. Nasrat, S.A. Mira and H.H. Fatani, Comparison of glycosylated fibrinogen, albumin, and haemoglobin as indices of blood glucose control in diabetic patients, Diabet Med 7 (9) (1990), pp. 819-824.

[16] E.J. Dunn, R.A. Ariens and P.J. Grant, The influence of type 2 diabetes on fibrin structure and function, Diabetologia 48 (6) (2005), pp. 1198-1206.

[17] C.H. Nair, A. Azhar, J.D. Wilson and D.P. Dhall, Studies on fibrin network structure in human plasma. Part II-Clinical application: diabetes and antidiabetic drugs, Thromb Res 64 (4) (1991), pp. 477-485.

[18] G. Jorneskog, N. Egberg, B. Fagrell, K. Fatah, B. Hessel and H. Johnsson et al., Altered properties of the fibrin gel structure in patients with IDDM, Diabetologia 39 (12) (1996), pp. 1519-1523. 
[19] M. Kitamura, K. Asai and F. Kuzuya, Clinical significance of measuring glycated fibrinogen in plasma in diabetes mellitus, Nippon Ronen Igakkai Zasshi 29 (5) (1992), pp. 396-402.

[20] S. Suzuki, M. Kokubu, E. Saito, J. Makise, M. Kanayama and M. Yamanaka, Assay of glycated fibrinogen in plasma as an indicator of blood glucose control, Rinsho Byori 38 (3) (1990), pp. 306-310.

[21] Standards of medical care in diabetes, Diabetes Care 27 (Suppl 1) (2004), pp. S15S35.

[22] W.T. Friedewald, R.I. Levy and D.S. Fredrickson, Estimation of the concentration of low-density lipoprotein cholesterol in plasma, without use of the preparative ultracentrifuge, Clin Chem 18 (6) (1972), pp. 499-502.

[23] A. Katz, S.S. Nambi, K. Mather, A.D. Baron, D.A. Follmann and G. Sullivan et al., Quantitative insulin sensitivity check index: a simple, accurate method for assessing insulin sensitivity in humans, J Clin Endocrinol Metab 85 (7) (2000), pp. 2402-2410. [24] M. Takebe, G. Soe, I. Kohno, T. Sugo and M. Matsuda, Calcium ion-dependent monoclonal antibody against human fibrinogen: preparation, characterization, and application to fibrinogen purification, Thromb Haemost 73 (4) (1995), pp. 662-667. [25] E.J. Dunn and R.A. Ariens, Fibrinogen and fibrin clot structure in diabetes, Herz 29 (5) (2004), pp. 470-479.

[26] J.C. Jerling, H.H. Vorster, W. Oosthuizen, N. Silvis and C.S. Venter, Differences in plasminogen activator inhibitor 1 activity between blacks and whites may be diet related, Haemostasis 24 (6) (1994), pp. 364-368.

[27] A.R. Folsom, K.K. Wu, M.G. Conlan, A. Finch, C.E. Davis and G. Marcucci et al., Distributions of hemostatic variables in blacks and whites: population reference values from the Atherosclerosis Risk in Communities (ARIC) Study, Ethn Dis 2 (1) (1992), pp. $35-46$.

[28] M.R. Hammer, P.N. John, M.D. Flynn, A.J. Bellingham and R.D. Leslie, Glycated fibrinogen: a new index of short-term diabetic control, Ann Clin Biochem 26 (Pt 1) (1989), pp. 58-62. 
[29] M.S. Ardawi, H.N. Nasrat, S.A. Mira and H.H. Fatani, Comparison of glycosylated fibrinogen, albumin, and haemoglobin as indices of blood glucose control in diabetic patients, Diabet Med 7 (9) (1990), pp. 819-824.

[30] S. Suzuki, M. Kokubu, E. Saito, J. Makise, M. Kanayama and M. Yamanaka, Assay of glycated fibrinogen in plasma as an indicator of blood glucose control, Rinsho Byori 38 (3) (1990), pp. 306-310.

[31] A. Lutjens, A.A. te Velde, E.A. vd Veen and vd MJ, Glycosylation of human fibrinogen in vivo, Diabetologia 28 (2) (1985), pp. 87-89.

[32] R. Fluckiger and K.H. Winterhalter, In vitro synthesis of hemoglobin AIc, FEBS Lett 71 (2) (1976), pp. 356-360.

[33] E. Schleicher and O.H. Wieland, Specific quantitation by HPLC of protein (lysine) bound glucose in human serum albumin and other glycosylated proteins, J Clin Chem Clin Biochem 19 (2) (1981), pp. 81-87.

[34] G.E. Austin, R.H. Mullins and L.G. Morin, Non-enzymic glycation of individual plasma proteins in normoglycemic and hyperglycemic patients, Clin Chem 33 (12) (1987), pp. 2220-2224.

[35] M. Kitamura, K. Asai and F. Kuzuya, Clinical significance of measuring glycated fibrinogen in plasma in diabetes mellitus, Nippon Ronen Igakkai Zasshi 29 (5) (1992), pp. 396-402.

[36] G.N. Rakhimova, Z.S. Akbarov and I. Tarakulov, Significance of glycated fibrinogen measurements in diabetes mellitus, Klin Lab Diagn 2 (1999), pp. 18-21.

Corresponding author. School of Physiology, Nutrition and Consumer Science, Department Nutrition, North-West University, Potchefstroom Campus, Private Bag X6001, Potchefstroom, 2520 South Africa. Tel.: +27 18299 2467; fax: +27 182992464. 